\title{
Charcot-Marie-Tooth disease type 2S
}

INSERM

\section{Source}

INSERM. (1999). Orphanet: an online rare disease and orphan drug data base. CharcotMarie-Tooth disease type 2S. ORPHA:443073

A rare subtype of axonal hereditary motor and sensory neuropathy characterized by progressive distal muscle weakness and atrophy of both the lower and upper limbs, absent or reduced deep tendon reflexes, mild sensory loss, foot drop, and pes cavus leading eventually to wheelchair dependance. Some patients present with early hypotonia and delayed motor development. Scoliosis and variable autonomic disturbances may be associated. 